\title{
(6) OPEN ACCESS \\ Risk factors for heat illness among British soldiers in the hot Collective Training Environment
}

\author{
Alice C Moore, ${ }^{1}$ M J Stacey, ${ }^{2,3}$ K G H Bailey, ${ }^{4}$ R J Bunn, ${ }^{5}$ D R Woods, ${ }^{2,6}$ \\ K J Haworth, ${ }^{4}$ S J Brett, ${ }^{3,7}$ S E F Folkes ${ }^{4}$
}

- Additional material is published online only. To view please visit the journal online (http://dx.doi.org/10.1136/ jramc-2015-000427).

For numbered affiliations see end of article.

\section{Correspondence to} Maj M J Stacey, Department of Surgery and Cancer, Imperial College, Hammersmith Hospital, Du Cane Road, London W120HS, UK; M.stacey13@imperial.ac.uk

Received 15 February 2015 Revised 16 March 2015 Accepted 16 April 2015 Published Online First 2 June 2015
CrossMark

To cite: Moore $A C$, Stacey MJ, Bailey KGH, et al. J R Army Med Corps 2016;162:434-439.

\section{ABSTRACT}

Background Heat illness is a preventable disorder in military populations. Measures that protect vulnerable individuals and contribute to effective Immediate Treatment may reduce the impact of heat illness, but depend upon adequate understanding and awareness among Commanders and their troops.

Objective To assess risk factors for heat illness in British soldiers deployed to the hot Collective Training Environment (CTE) and to explore awareness of Immediate Treatment responses.

Methods An anonymous questionnaire was distributed to British soldiers deployed in the hot CTEs of Kenya and Canada. Responses were analysed to determine the prevalence of individual (Intrinsic) and Command-practice (Extrinsic) risk factors for heat illness and the selfreported awareness of key Immediate Treatment priorities (recognition, first aid and casualty evacuation).

Results The prevalence of Intrinsic risk factors was relatively low in comparison with Extrinsic risk factors. The majority of respondents were aware of key Immediate Treatment responses. The most frequently reported factors in each domain were increased risk by body composition scoring, inadequate time for heat acclimatisation and insufficient briefing about casualty evacuation.

Conclusions Novel data on the distribution and scale of risk factors for heat illness are presented. A collective approach to risk reduction by the accumulation of 'marginal gains' is proposed for the UK military. This should focus on limiting Intrinsic risk factors before deployment, reducing Extrinsic factors during training and promoting timely Immediate Treatment responses within the hot CTE.

\section{INTRODUCTION}

In the UK military, heat illness is an important cause of morbidity that may arise during training ${ }^{1-3}$ and on deployed operations. ${ }^{3-6}$ It occurs when excessive body heat develops under conditions of increased heat stress, to which physical exertion and impaired thermoregulatory capacity may contribute. ${ }^{7}$ The effects of heat illness range from mild symptoms, such as muscular weakness and headache, to severe manifestations, including collapse, coma and death. ${ }^{5} 89$ The clinical sequelae experienced by individual soldiers can impact upon operational effectiveness in the wider Service, both proximal to the episode such as interruption or termination of training or mission, immediate treatment and casualty evacuation requirements, acute loss of manpower and subsequently, such as contribution to chronic undermanning, external imposition of restraints to training, critical media coverage.
Key messages

Among military personnel, susceptibility to severe heat illness is understood in relation to individual (Intrinsic) and Command-practice (Extrinsic) risk factors, as well as to the effectiveness of Immediate Treatment.

- In responses to a questionnaire completed by UK troops deployed to the hot Collective Training Environment (CTE), the prevalence of Intrinsic risk factors was low in comparison with Extrinsic risk factors.

- Intrinsic risk factors would be further reduced by optimising body composition and physical fitness predeployment, whereas improved logistics and appropriate use of Medical support could limit Extrinsic risks during training.

- The majority of respondents were aware of key Immediate Treatment responses.

- Prevention of heat illness can be seen as a 'marginal gains' process, requiring multiple small improvements before and during deployment to reduce the overall impact in the hot CTE.

Effective immediate treatment may prove lifesaving in cases of severe heat illness, ${ }^{10}$ though the disorder remains more preventable than treatable. ${ }^{11}$ This view is endorsed by the UK Ministry of Defence (MoD) in Joint Service Publication 539 (JSP 539), ${ }^{8}$ which provides practical guidance on how to reduce the risk of heat illness to as low as reasonably practical. At the tactical level, commanders are expected to identify enhanced susceptibility to heat illness, which can be considered as the individual (intrinsic) risk allied to the commandpractice (extrinsic) risk (Table 1). Many of these risk factors are potentially modifiable, so prospective awareness of their scale and distribution may be key to reducing heat-related morbidity. For example, overweight individuals are at disproportionate risk of heat illness and may be identified by body composition measurement (BCM), which is routinely reported in the UK Armed Forces. Engaging at-risk personnel in weight management and healthy weight maintenance strategies could reduce the prevalence of this intrinsic risk factor for heat illness within the Force. ${ }^{12}$

This is important, because the UK military trains in physically austere environments, with the aim of 
Table 1 Risk factors for heat illness during military activities ${ }^{8} 10$

\begin{tabular}{ll}
\hline Intrinsic risk factors & Extrinsic risk factors \\
\hline $\begin{array}{l}\text { Low level of physical fitness } \\
\text { Obesity/excess body fat/high BMI* }\end{array}$ & $\begin{array}{l}\text { Sleep deprivation } \\
\text { Dehydration (insufficient water intake } \\
\text { or excessive loss) }\end{array}$ \\
$\begin{array}{l}\text { Medications (eg, antihistamines, } \\
\beta \text {-blockers) }\end{array}$ & Nutritional deficit \\
$\begin{array}{l}\text { Intercurrent illness (eg, gastroenteritis, } \\
\text { cellulitis) }\end{array}$ & Inadequate heat acclimatisation \\
$\begin{array}{l}\text { Chronic disease states (eg, } \\
\text { cardiovascular disease, sickle cell trait) } \\
\text { Older age (>40 years old) }\end{array}$ & $\begin{array}{l}\text { Type of activity (eg, running or } \\
\text { loaded route march) }\end{array}$ \\
& $\begin{array}{l}\text { Type of clothing } \\
\text { eg, body armour, impermeable and/ } \\
\text { or encapsulating uniform }\end{array}$ \\
\hline
\end{tabular}

${ }^{*}$ Categorised by body composition measurement (BCM) in UK military personnel, according to associated general health risk.

BMI, body mass index.

subjecting troops and equipment to conditions relevant to operational deployment. In the hot Collective Training Environment (CTE), visiting troops take part in exercises up to Battlegroup (BG) level, with the support of locally based Permanent Training Staff (PTS). These duties present a risk of heat illness to both types of personnel and are therefore subject to the control measures prescribed in JSP 539. In support of a wider evaluation of compliance with JSP 539 in the hot CTE, we undertook a questionnaire-based project to investigate the prevalence of factors associated with heat illness. Our primary aim was to assess the burden of Intrinsic and Extrinsic risk factors for heat illness among British soldiers deployed to the hot CTE. Our secondary aim was to explore awareness of Immediate Treatment priorities for suspected heat illness.

\section{METHODS}

In June and July 2014, an Occupational Health team from the Headquarters of the Army Recruiting and Training Division conducted assurance visits to the British Army Training Unit Kenya (BATUK) and the British Army Training Unit Suffield (BATUS) in Canada. Their objective was to evaluate the delivery of Collective Training in accordance with JSP 539. Both visits were scheduled to coincide with hot-weather training and were supported by the Army Medical Directorate Environmental Monitoring Team. In advance of the assurance visits, authority to conduct a questionnaire-based survey was granted by Joint Medical Command, (JMC reference RCDM/Res/Audit/1036/ 14/0411), who confirmed that formal ethical approval was not required by the MoD Research Ethics Committee.

The questionnaire was constructed to assess for the presence of Intrinsic and Extrinsic risk factors for heat illness, in addition to self-reported awareness of Immediate Treatment actions (see online supplementary material). Numerical, categorical, multiple choice and polar ('yes'/'no') questions were used. For certain questions predetermined criteria were used to identify responses indicating enhanced risk of heat illness (Table 2). Baseline characteristics of the respondents were also gathered to inform the interpretation of results. In each CTE, PTS were nominated to distribute 325 copies of the questionnaire among exercising BG personnel and fellow PTS. Completion of the questionnaire was voluntary and 7 days were allowed for its distribution and return.

\section{RESULTS}

Responses were analysed by individual CTE and also after pooling results. Lack of response to a question was recorded as 'No Response' (NR). Out of 650 questionnaires distributed across both CTEs, 250 (38.5\%) were returned adequate for analysis with this rate differing between BATUK (178 returns, $54.8 \%$ ) and BATUS (72 returns, 22.2\%) (Table 3).

The combined data of BATUK and BATUS of reported frequency of risk factors for heat illness in the hot CTE are given in Table 4.

Figure 1 shows self-reported awareness of measures that can mitigate the severity of evolving or established heat illness. Responses to three key questions are displayed as the proportion of respondents in each occupational category (Junior Ranks, Senior Ranks, Commissioned Officers) who were aware, or were not aware, of each measure, or who made NR.

\section{DISCUSSION}

This is the first evaluation of intrinsic and extrinsic risk factors for heat illness in a UK military population. It is also the first published report to address the practical application of JSP 539 in the hot CTE. The key findings relate to the frequencies of self-reported risk factors for heat illness, which were relatively low for intrinsic factors and higher for extrinsic factors. If these results are representative of the typical training population deployed to the hot CTE, it would appear that the impact of

Table 2 Criteria for enhanced risk of heat illness, by categorical response

\begin{tabular}{|c|c|c|c|}
\hline Intrinsic risk factors & Related question & $\begin{array}{l}\text { Response indicating no } \\
\text { enhanced risk }\end{array}$ & $\begin{array}{l}\text { Response indicating } \\
\text { enhanced risk }\end{array}$ \\
\hline Low level of fitness & How do you judge your fitness at the moment? & $\begin{array}{l}\text { Moderately Fit or } \\
\text { Trained or } \\
\text { Well Trained }\end{array}$ & Unfit or Inactive \\
\hline Low frequency of physical exercise & $\begin{array}{l}\text { How many times a week do you undertake physical exercise } \\
\text { lasting at least } 45 \mathrm{~min} \text { ? }\end{array}$ & $\geq 3$ times/week & $<3$ times/week \\
\hline High BMI, high \% body fat mass & What is your BCM category, if known? & No increased health risk & $\begin{array}{l}\text { Increased Risk or } \\
\text { High Risk or } \\
\text { Very High Risk or Extreme } \\
\text { Risk }\end{array}$ \\
\hline $\begin{array}{l}\text { Dehydration, nutritional deficit, sleep } \\
\text { deprivation }\end{array}$ & While training, have you felt dehydrated/hungry/sleep deprived? & $\begin{array}{l}\text { Not At All or } \\
\text { Some of the Times }\end{array}$ & Most of the Time or Always \\
\hline Intercurrent IIIness & $\begin{array}{l}\text { Have you continued training while feeling unwell (eg, cold/ } \\
\text { diarrhoea) during this exercise? }\end{array}$ & No & Yes \\
\hline
\end{tabular}


Table 3 Characteristics of respondents engaged in collective training in Kenya (BATUK) and Canada (BATUS)

\begin{tabular}{|c|c|c|c|}
\hline & BATUK $(n=178)$ & BATUS ( $n=72)$ & Overall $(n=250)$ \\
\hline \multicolumn{4}{|l|}{ Rank } \\
\hline Junior ranks & $143(80.3 \%)$ & $56(77.8 \%)$ & $199(79.6 \%)$ \\
\hline Senior ranks & $21(11.8 \%)$ & $6(8.3 \%)$ & $27(10.8 \%)$ \\
\hline Commissioned officers & $14(7.9 \%)$ & $10(13.9 \%)$ & $24(9.6 \%)$ \\
\hline \multicolumn{4}{|l|}{ Role } \\
\hline BG: Forward subunits (Rifle Coys, Armoured Squadrons, attached Arms) & $95(53.4 \%)$ & $72(100.0 \%)$ & $167(66.8 \%)$ \\
\hline BG: Rear echelon (HQ Coy elements not deployed to the main training area) & $54(30.3 \%)$ & $0(0.0 \%)$ & $54(21.6 \%)$ \\
\hline BG: Medical assets & $11(6.2 \%)$ & $0(0.0 \%)$ & $11(4.4 \%)$ \\
\hline PTS & $17(9.6 \%)$ & $0(0.0 \%)$ & $17(6.8 \%)$ \\
\hline NR & $1(0.6 \%)$ & $0(0.0 \%)$ & $1(0.4 \%)$ \\
\hline Median (range) days since arrival incountry* & $21(12-42)(n=143)$ & $31(19-120)(n=69)$ & $22(12-120)(n=212)$ \\
\hline \multicolumn{4}{|l|}{ Medical Employment Standard } \\
\hline No medical sanction & $151(84.8 \%)$ & $65(90.3 \%)$ & $216(86.4 \%)$ \\
\hline Medically downgraded & $20(11.2 \%)$ & $5(6.9 \%)$ & $25(10.0 \%)$ \\
\hline NR & $7(3.9 \%)$ & $2(2.8 \%)$ & $9(3.6 \%)$ \\
\hline \multicolumn{4}{|l|}{ Lifestyle factors } \\
\hline Use of dietary/exercise supplements & $12(6.7 \%)$ & $9(12.5 \%)$ & $20(8.0 \%)$ \\
\hline Active tobacco smoking & $66(37.1 \%)$ & $39(54.2 \%)$ & $105(42.0 \%)$ \\
\hline
\end{tabular}

heat stress can be managed to a low level by protecting vulnerable individuals, optimising preventive Command practices and making timely and appropriate responses to suspected heat illness. Before this hypothesis is explored further, it is necessary to address the question of whether our findings can be considered sufficiently representative to make wider generalisations.

\section{Respondent characteristics and generalisability to other} military cohorts

Of all heat illness notified within the British Army between 2009 and 2013, 65\% was reported by training units and
sub-Saharan Africa and North America accounted for nearly a quarter of all overseas notifications. ${ }^{3}$ There are grounds, therefore, to expect that mitigating the risk heat illness in BATUK and BATUS will reduce the impact of heat-related morbidity in the wider Service. The findings of the present project must be interpreted with caution, however, because of the relatively small number of respondents within each hot CTE and the likelihood of enrolment bias. The results presented are based upon voluntary responses to a questionnaire that PTS distributed and collected. This was the only way that sufficient numbers of potential respondents could be accessed in large and remote

Table 4 Distribution of risk factors for heat illness reported by 250 British soldiers in the hot CTE, according to Intrinsic and Extrinsic risk factors

\begin{tabular}{|c|c|c|c|}
\hline & $\begin{array}{l}\text { Number of personnel with risk } \\
\text { factor }(\%)\end{array}$ & $\begin{array}{l}\text { Number of personnel without risk } \\
\text { factor }(\%)\end{array}$ & $\begin{array}{l}\text { Number of personnel making no } \\
\text { response (\%) }\end{array}$ \\
\hline \multicolumn{4}{|l|}{ Intrinsic risk factor } \\
\hline Low level of physical fitness & $18(7.2)$ & $232(92.8)$ & $0(0.0)$ \\
\hline Low frequency of physical exercise & $28(11.2)$ & $222(88.8)$ & $0(0.0)$ \\
\hline 1.5 mile run time $>12 \min ^{*}$ & $9(3.6)$ & $240(96.0)$ & $1(0.4)$ \\
\hline Elevated health risk from $\mathrm{BCM}$ & $34(13.6)$ & $172(68.8)$ & $44(17.6)$ \\
\hline Previous heat illness & $16(6.4)$ & $230(92.0)$ & $4(1.6)$ \\
\hline Possible intercurrent illness & $16(6.4)$ & $233(93.2)$ & $1(0.4)$ \\
\hline $\begin{array}{l}\text { Regular use of risk-associated medications } \\
\text { (eg, NSAIDs, antihistamines, } \beta \text {-blockers) }\end{array}$ & $12(4.8)$ & $231(92.4)$ & $7(2.8)$ \\
\hline \multicolumn{4}{|l|}{ Extrinsic risk factor } \\
\hline \multicolumn{4}{|l|}{ Upon arrival to the hot CTE } \\
\hline Acclimatisation programme $<7$ days & $208(83.2)$ & $34(13.6)$ & $8(3.2)$ \\
\hline No acclimatisation programme & $106(42.4)$ & $136(54.4)$ & $8(3.2)$ \\
\hline \multicolumn{4}{|l|}{ During training in the hot CTE } \\
\hline Feelings of dehydration & $45(18.0)$ & $205(82.0)$ & $0(0.0)$ \\
\hline Hunger & $53(21.2)$ & $197(78.8)$ & $0(0.0)$ \\
\hline Sleep deprivation & $83(33.2)$ & $166(66.4)$ & $1(0.4)$ \\
\hline Trained while feeling unwell & $98(39.2)$ & $148(59.2))$ & $4(1.6)$ \\
\hline
\end{tabular}




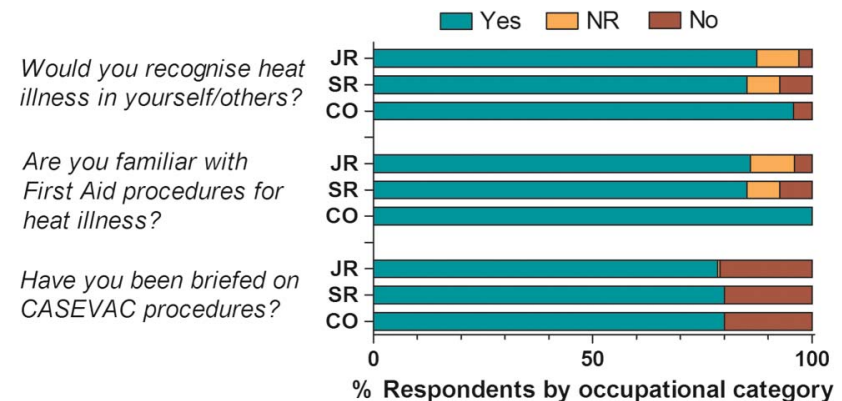

Figure 1 Awareness of key measures to mitigate heat illness reported by British soldiers in the hot Collective Training Environment (CTE). Responses are displayed by occupational category (JR, Junior Ranks; SR, Senior Ranks; CO, Commissioned Officers) as either aware (Yes), unaware (No) or No Response (NR).

training areas, but may have contributed to the relatively low return rate $(38.5 \%)$ and biased the sample of each BG. For the questionnaires that were returned, the majority of respondents were found to be Junior Ranks (79.6\%) and nearly all respondents were deployed as part of a Combat Arms BG (92.8\%). Among these returns, the ratio of respondents deployed in the main training area to those held in the rear echelon (ie, forward:rear) was a little over 3:1. At least $10 \%$ of respondents were medically downgraded, up to $4 \%$ were unable to complete a 1.5 mile run in under $12 \mathrm{~min}$ and at least $13 \%$ were adjudged to be at increased risk of adverse health outcomes on the basis of BCM scoring.

The bias towards rear echelon personnel arose in returns from BATUK and provides a basis for including returns from BATUS, which were made exclusively by 'Forward' BG troops, albeit at a very poor rate of response. Overall, the respondent characteristics appear quite similar to those of the BG populations sampled and to available British Army figures. Within the same training year, 94-98\% of personnel in the units contributing to each BG had achieved a 1.5-mile run time categorised as 'Good', which is $<12$ min in men aged under 44 years old. The proportion of individuals placed at 'increased risk' or greater by BCM scoring varied from $14 \%$ to $24 \%$ among contributing units and, in the wider Army, the medically downgraded rate was as high as $\sim 21 \% .^{13}$ The proportion of respondents making NR within each area of these areas of enquiry was not dissimilar to the percentage of missing records at each unit (ie, the proportion of personnel without a documented 1.5 mile run time or BCM score). It would appear, then, that any bias towards rear echelon personnel did not grossly compromise the sample in the direction of poorer run times or greater BCM risk (versus the wider BG populations) or greater pre-existing medical morbidity compared with the British Army as a whole.

Recent data concerning physical activity levels have been published for Army personnel based at UK training establishments, including recruits, in whom just $1.0 \%$ of respondents described their physical activity levels as 'low'. ${ }^{14}$ Respondents in BATUK and BATUS were self-reportedly 'inactive' or 'unfit' in $7.2 \%$ of cases and $11.2 \%$ engaged in physical exercise less than three times a week, but this apparent variation may simply reflect the difference between physical activity levels in personnel based at deployable field units versus those undergoing training and selection courses in the UK. If these uncertainties are borne in mind, then respondents in BATUK and BATUS may be considered sufficiently representative of their parent units to draw preliminary conclusions. The following considerations may, therefore, be of value to similar BGs deploying into the hot CTE.
Intrinsic risk of heat illness

The overall prevalence of intrinsic risk factors for heat illness appeared low, but a number of individuals were judged to be at enhanced risk in relation to personal fitness standards and BCM category. In the absence of data specific to the trained strength of the UK military (men and women), relationships between physical fitness standards and risk of military heat illness have been derived from studies of male recruits to US Armed Forces. During US Army basic training, low levels of physical fitness ${ }^{15}$ and excessive body fat $^{16}$ have been shown to be independent predictors of heat illness and US Marine Corps recruits with body mass index (BMI) $\geq 22 \mathrm{~kg} / \mathrm{m}^{2}$ who took 12 min or more to complete a 1.5 mile run were at eightfold greater risk of heat illness versus those with faster run times and lower BMI. ${ }^{17}$ While medical downgrading per se may not increase the risk of heat illness, individuals who are unable to maintain frequent exercise regimens and fitness levels may be placed at increased risk during military training. ${ }^{18}$ Of respondents to the questionnaire reported here, no more than $4 \%$ had failed to achieve a 1.5 mile run time of below $12 \mathrm{~min}$, despite the $10 \%$ medicaldowngrading rate, whereas $13.6 \%$ reported an elevated BCM score. By inference, the size of the threat of heat illness from excessive body fat and higher BMI may have been greater than that associated with poor aerobic fitness and downgraded Medical Employment Standard. This is relevant, because fitness and body composition have the potential to be improved in a graded and safe manner before arrival to the hot CTE, but may need to be approached in different ways (eg, types of training, dietary strategies).

Less prevalent risk factors included a previous history of heat illness (6.4\%), possible intercurrent illness (6.4\%) and use of medications that may predispose to heat illness $(4.8 \%)$. These could be reduced further, by appropriate predeployment risk assessment of personnel previously affected by heat illness and prompt medical assessment of suspected illness-including heat illness-within the hot CTE.

\section{Extrinsic risk of heat illness}

This project was conducted as part of a wider evaluation of compliance with JSP 539 in the hot CTE. This reported a mature and well developed approach to reducing extrinsic risk factors, but also identified a critical shortfall in the time allowed for heat acclimatisation. Seven days is specified in JSP $539,^{8}$ yet periods of shorter length were reported by $83.2 \%$ of respondents, of whom more than half reported no recognisable acclimatisation programme. Other investigations confirmed that inadequate time had been allocated for troops to acclimatise, with requirements for handover/takeover of equipment and other logistic constraints cited as contributory factors. In unacclimatised personnel undertaking strenuous physical activity, heat illness peaks during the first few days in a hot environment. ${ }^{19}$ Taking heat illness casualties early in the course of an exercise will maximally impact upon BG training objectives, due to the medical imperative to remove them from the hot CTE.

In mitigation of these alarming statistics, it should be noted that 54 respondents were based with the rear echelon in Kenya at the time of completing the survey, where the baseline threat of heat illness from the environment and physical activity is substantially lower than in the training area itself. Excluding these troops from the requirement for acclimatisation would effectively halve the proportion of respondents who reported no recognisable heat acclimatisation programme, to approximately $21.0 \%$ of all respondents. In common with some PTS, however, 
rear echelon troops may be expected to sporadically deploy forwards to the hot CTE itself and special consideration must be given to how the risk of heat illness can be reduced on these occasions. For personnel more permanently based in the hot CTE, future BATUK/BATUS training schedules should include adequate time for heat acclimatisation and BG staff must find imaginative ways of incorporating acclimatisation serials into other routine activity, before formal training begins.

Other areas of extrinsic risk that are directly influenced by Command practices include the provision of hydration, nutrition, sleep and rest. Difficulties in meeting these requirements are recognised features of military operations ${ }^{20} 21$ and appear to have affected $20-30 \%$ of respondents in BATUK and BATUS. For UK military personnel, JSP 539 places responsibility upon Commanders to ensure that troops drink sufficient water before, during and after activities associated with a risk of heat illness. ${ }^{8}$ Implicit to this instruction is the task of delivering adequate amounts of potable water, at the correct time and to accessible locations within the hot CTE, and the same requirement holds true for food rations. Some Commanders may ascribe to a practice of putative 'preconditioning' for military operations, through depriving personnel of sleep, providing a diet inadequate to maintain energy balance and enforcing severe water discipline during training. Any perceived benefits of this approach must be weighed against the established evidence for reduced training performance ${ }^{22}$ and increased heat illness risk under such conditions. ${ }^{23}$ It is essential that planners in the BG and PTS pay heed to these considerations in the construction of individual training serials and in the phasing of the broader exercise.

The practice of 'soldiering on' through minor illness is also relevant to Command practices. ${ }^{8}$ Training while feeling unwell was reported by $39.2 \%$ of respondents, including a significant proportion of Senior Ranks and Commissioned Officers (31.4\%). These findings emphasise the importance of providing close medical support to troops exercising in the hot CTE, in order to facilitate safe training. At a single point in time, medical personnel may be required to assess the healthcare needs and training suitability of only a small number of unwell troops, but a large proportion of the $\mathrm{BG}$ may require this service over the course of an entire exercise if heat illness is to be avoided.

\section{Immediate treatment for suspected heat illness}

Methods for the prevention of heat illness are more effective than those available for its treatment. ${ }^{11}$ When prevention fails, measures to reduce the severity of illness include early recognition, appropriate first aid management and prompt evacuation to medical care. ${ }^{10}$ Compared with training in the Firm Base, deployment to the hot CTE may be associated with additional constraints to monitoring and responding to critical heat stress, secondary to realistic simulation of operational deployment. This requires Service personnel to possess a basic but firm grasp of how heat stress and heat illness are mitigated. Our results show that most respondents felt confident in this regard, though actual knowledge relating to immediate treatment was not assessed and some of this confidence may have been misplaced. The largest shortfall in awareness concerned casualty evacuation, with almost a quarter of the surveyed population reportedly receiving no formal briefing of procedures to initiate this. The number of personnel from the Ranks who made NR to questions about the recognition and treatment of heat illness was not insubstantial. When these responses are combined with those declaring frank lack of knowledge, a significant area of modifiable risk emerges. This could be addressed by ensuring appropriate education and direction on the response to heat illness, in advance of deployment and on arrival to the hot CTE.

\section{Additional considerations}

In the populations surveyed, respondents from the Combat Arms are expected to have predominated over those from other Arms and Services and markedly different risk profiles may prevail in formations weighted towards other capabilities such as engineering and medical. Given that the proportion of respondents subject to medical downgrading in BATUS and BATUK (10.4\%) was only half that reported for the Army during the same year $(21 \%),{ }^{13}$ it is possible that the reported risk of heat illness was lower than would be found in a Force more widely representative of the British Army.

The respondent smoking rate of $42.0 \%$ was in agreement with the work of Boos et $a l^{24}$ who reported a prevalence of $46.0 \%$ in British soldiers deployed to the hot operational environment of southern Afghanistan in 2010 and 42.0\% among regular British Army troops at point of deployment to Iraq in 2003. ${ }^{25}$ A recent study of Army training establishments in the UK found a lower, but still substantial, smoking prevalence of $29 \%{ }^{14}$ Direct evidence of a role for tobacco in the development of heat illness is lacking, but smoking-associated risks that could precipitate or contribute to an episode in military personnel include decreased physical fitness ${ }^{26} 27$ and intercurrent illness. $^{19} 28 \quad 29$ It is disappointing that the requirement to achieve significant reductions in smoking among British Army personnel ${ }^{2325}$ is yet to be met in the training environment and a fresh approach to prevention may be required. In contrast, the use of dietary and exercise supplements was much lower than reported for UK military personnel deployed on operations to Afghanistan in $2010(40.2 \%)^{24}$ and Iraq in $2009(32.0 \%)^{30}$ and for British Army personnel attending UK-based training establishments in 2010/2011 (38\%). ${ }^{14}$ If corroborated in a larger study, this finding may reflect the impact of recent efforts within the UK military to reduce illicit, unnecessary and potentially dangerous ${ }^{31}$ supplementation practices.

\section{Future research}

To minimise the risk of heat illness in the hot CTE, Commanders and Medical personnel are required to implement the guidance from JSP 539 in a dynamic and comprehensive fashion. Processes of similar complexity are encountered in civilian practice, where there is a growing appreciation of the large benefits that may accrue from aggregating multiple, seemingly miniscule, improvements. Having met with success in the arena of professional sport, ${ }^{32}$ proponents of 'marginal gains' theory are developing this approach to improve clinical outcomes in high-risk healthcare settings. ${ }^{33}$ Future research should address whether heat illness can be reduced-or even eliminated-by coordinating attempts to proactively identify and modify the multiple risk factors that may exist in different UK military populations and CTEs.

An emerging area of academic and practical interest is centred on the differential responses to heat stress and exercise observed between male and female subjects. ${ }^{34}{ }^{35}$ Female soldiers and officers were known to be represented in only small numbers among the BG and PTS populations surveyed and permission to undertake the project was subject to gender anonymity, because of the risk of identifying female respondents by their stated rank and other characteristics. With the emergence of women in front line roles on recent deployments, and female entry into the Combat Arms ensuing from recent MoD policy changes, the 
relevance of intrinsic risk factors that have been described in largely male military cohorts should be investigated with particular regard to female Service personnel.

\section{CONCLUSIONS}

This evaluation highlights the significant challenge of preventing heat illness in the hot CTE. The threat posed by heat illness is seen to prevail in multiple domains, where risk factors must be recognised before modification or mitigation is possible. The most frequently reported factors within each domain were excess body fat/high BMI (as indicated by BCM category), inadequate time for heat acclimatisation and incomplete briefing of Casualty Evacuation (CASEVAC) procedures.

It is important, therefore, that BGs are mindful of the need for prior preparation of personnel and correct implementation of the guidance provided in JSP 539, in advance of deployment to the hot CTE. Once arrived in BATUK/BATUS, particular attention should be paid to ensuring adequate heat acclimatisation, sensible training practices and timely Immediate Treatment of suspected heat illness cases.

Future research should determine the particular risks harboured by other training populations, including female cohorts, and within different CTEs. The question of whether serious heat illness can be eliminated from UK military practice by engagement in a 'marginal gains' approach to risk reduction also merits attention. This should enfranchise the full spectrum of personnel who influence the incidence of heat illness within the hot CTE, including key BG members and PTS.

\section{Author affiliations \\ ${ }^{1}$ Department of Medicine, Frimley Health Foundation Trust, Frimley, UK ${ }^{2}$ Department of Military Medicine, RCDM, Birmingham, UK \\ ${ }^{3}$ Department of Surgery and Cancer, Imperial College London, London, UK ${ }^{4}$ Occupational Medicine, Headquarters Army Recruiting and Training Division, Upavon, Wiltshire, UK \\ ${ }^{5}$ Environmental Monitoring Team, Army Medical Directorate, Camberley, UK ${ }^{6}$ Carnegie Research Institute, Leeds Beckett University, Leeds, UK ${ }^{7}$ General Intensive Care Unit, Hammersmith Hospital, Du Cane Road, Greater London, UK}

Contributors $A C M, M J S$ and KGB are responsible for the overall content as guarantors. All eight authors meet the authorship criteria endorsed by $B M J$ : substantial contributions to the conception of the work; drafting and revising the work critically for important intellectual content; final approval of the version to be published; agreement to be accountable for all aspects of the work in ensuring that questions related to the accuracy or integrity of any part of the work are appropriately investigated and resolved.

Competing interests None declared.

Provenance and peer review Not commissioned; externally peer reviewed.

Open Access This is an Open Access article distributed in accordance with the Creative Commons Attribution Non Commercial (CC BY-NC 4.0) license, which permits others to distribute, remix, adapt, build upon this work non-commercially, and license their derivative works on different terms, provided the original work is properly cited and the use is non-commercial. See: http://creativecommons.org/ licenses/by-nc/4.0/

\section{REFERENCES}

1 Bricknell M. Heat illness: a comparison between UK and Cyprus reports. J R Army Med Corps 1996;142:59-61.

2 Finnegan TP. Heat illness in the services. J R Army Med Corps 1994;140:161-2.

3 Stacey MJ, Brett SB, Woods DR, et al. Case ascertainment of heat illness in the British Army: evidence of under-reporting from analysis of Medical and Command notifications, 2009-2013. J R Army Med Corps 2016;162: 428-33.

4 Grainge $C$, Heber M. The role of the physician in modern military operations: 12 months experience in Southern Iraq. J R Army Med Corps 2005;151:101-4.
5 Bolton JP, Gilbert PH, Tamayo C. Heat illness on Operation Telic in summer 2003: the experience of the Heat Illness Treatment Unit in northern Kuwait. J R Army Med Corps 2003;152:148-55

6 Cox AT, Lentaigne J, White $S$, et al. A two year review of the general internal medicine admissions to the British role 3 Hospital in Camp Bastion, Afghanistan. J R Army Med Corps 2015.

7 Sawka MN, Leon LR, Montain SJ and, et al. Integrated physiological mechanisms of exercise performance, adaptation, and maladaptation to heat stress. Compr Physiol 2011;1:1883-928.

8 Headquarters of the Surgeon General. Joint Service Publication 539 version 2.4 . Climatic illness and injury in the Armed Forces: Force Protection and initial medical treatment. August 2014.

9 World MJ, Booth TC. Iraq: the environmental challenge to HM land forces. Clin Med 2008;8:399-403.

10 Hunt PA, Smith JE. Heat illness. J R Army Med Corps 2005;151:234-42.

11 Leon LR and Helwig BG. Heat stroke: role of the systemic inflammatory response. J App/ Physiol 2010;109:1980-8.

12 DCDS (Pers) Service Conditions and Welfare. DIN 01-181. Armed Forces Weight Management Policy. September 2009.

13 FOI release. Number of service personnel who have been medically downgraded. https://www.gov.uk/government/publications/number-of-service-personnel-whohave-been-medically-downgraded. 11 April 2014.

14 Casey A, Hughes J, Izard RM, et al. Supplement use by UK-based British Army soldiers in training. Br J Nutr 2014;112:1175-84.

15 Bedno SA, Urban N, Boivin MR, et al. Fitness, obesity and risk of heat illness among army trainees. Occup Med (Lond). 2014;64:461-7.

16 Bedno SA, Li Y, Han W, et al. Exertional heat illness among overweight U.S. Army recruits in basic training. Aviat Space Environ Med 2010;81:107-11.

17 Gardner JW, Kark JA, Karnei K, et al. Risk factors predicting exertional heat illness in male Marine Corps recruits. Med Sci Sports Exerc 1996:28:939-44.

18 Rav-Acha M, Hadad E, Epstein Y, et al. Fatal exertional heat stroke: a case series. Am J Med Sci 2004;328:84-7.

19 Leon LR, Kenefick RW. Pathophysiology of heat-related illnesses. In: Auerbach PS, ed. Textbook of wilderness medicine. 6th edn. Philadelphia, PA: Mosby, 2012:215-31.

20 Goldman RF. Introduction to heat-related problems in military operations. In Pandolf KB, Burr RE, eds. Section 1: Hot environments. Medical aspects of Harsh Environments. Vol. 2. Washington DC: Borden Institute, 2002:3-50.

21 Fallowfield JL, Delves SK, Hill NE, et al. Energy expenditure, nutritional status, body composition and physical fitness of Royal Marines during a 6-month operational deployment in Afghanistan. Br J Nutr. 2014;112:821-9.

22 Nybo L, Rasmussen P, Sawka MN. Performance in the heat-physiological factors of importance for hyperthermia-induced fatique. Compr Physiol 2014;4:657-89.

23 Shapiro Y, Seidman DS. Field and clinical observations of exertional heat stroke patients. Med Sci Sports Exerc 1990;22:6-14.

24 Boos CJ, Simms P, Morris FR, et al. The use of exercise and dietary supplements among British soldiers in Afghanistan. J R Army Med Corps 2011;157: 229-32

25 Boos CJ, Croft AM. Smoking rates in the staff of a military field hospital before and after wartime deployment. J R Soc Med 2004:97:20-2.

26 Hoad NA, Clay DN. Smoking impairs the response to a physical training regime: a study of officer cadets. J R Army Med Corps 1992;138:115-17.

27 Cosio-Lima L, Brown K, Reynolds KL, et al. Injury and illness incidence in a Sergeants Major Academy class. Mil Med. 2013;178:735-41.

28 Klement $\mathrm{E}$, Talkington DF, Wasserzug $\mathrm{O}$, et al. Identification of risk factors for infection in an outbreak of Mycoplasma pneumoniae respiratory tract disease. Clin Infect Dis. 2006;43:1239-45.

29 Tas D, Sevketbeyoglu H, Aydin AF, et al. The relationship between nicotine dependence level and community-acquired pneumonia in young soldiers: a case control study. Intern Med. 2008;47:2117-20.

30 Boos CJ, Wheble GA, Campbell MJ, et al. Self-administration of exercise and dietary supplements in deployed British military personnel during Operation TELIC 13. J R Army Med Corps 2010;156:32-6.

31 Oh RC, Henning JS. Exertional heatstroke in an infantry soldier taking ephedra-containing dietary supplements. Mil Med 2003;168:429-30.

32 Slater S. Olympics cycling: marginal gains underpin Team GB dominance, 8 August 2012. http://www.bbc.co.uk/sport//olympics/19174302 (accessed 26 Jan 2015).

33 Durrand JW, Batterham AM, Danjoux GR. Pre-habilitation. I: aggregation of marginal gains. Anaesthesia 2014;69:403-6.

34 Druyan A, Makranz C, Moran D, et al. Heat tolerance in women-reconsidering the criteria. Aviat Space Environ Med 2012;83:58-60.

35 Lisman P, Kazman JB, O'Connor FG, et al. Heat tolerance testing: association between heat intolerance and anthropometric and fitness measurements. Mil Med 2014;179:1339-46. 